\title{
PSYCHOACTIVE SUBSTANCE INTAKE AND GENDER ON CRIME
}

\author{
A. A. OKEDIJI, M. U. NNAMANI, O. O. OJIJI, K. B. SANNI AND O. O. UMOH
}

(Received 17, September 2008; Revision Accepted 22, February 2009)

\begin{abstract}
This study investigated the influence of psychoactive substance (alcohol, marijuana, and cocaine) intake and gender on crime. Three hundred and eighty participants (380) were randomly selected from inmates as models of prisons in Uyo, Akwa Ibom State. The participants comprised 314 males $(82.63 \%)$ and 66 females $(17.37 \%)$ with the mean age of 28.3 years. The design of the study was a survey. In this study four hypotheses were predicted. The first hypothesis indicates that there was a statistically significant influence of alcohol intake on crime committed among prisoners, $X^{2}(\mathrm{df}=4, \mathrm{~N}=$ $380)=29.51, p<0.01$. The result of the second hypothesis indicates that there was also a significant influence of marijuana intake on crimes committed among prisoners, $X^{2}(4, N=380)=38.1, p<0.01$. Hypothesis three indicates that Cocaine intake does not significantly influence crime committed among prisoners, $X^{2}(4, N=380)=12.32$, ns. While the result of hypothesis four indicates there was no significant difference in crimes committed among male and female prisoners, $X^{2}(2, N=380)=0.12$, ns. The findings of the present study were discussed in the context of previous studies. The policy implications of the findings in this study were also discussed.
\end{abstract}

KEYWORD: Psychoactive Substance, Substance Intake, Gender, Crime, Prisoners

\section{INTRODUCTION}

The concept of crime as a wrong against the society is a very old one; and indeed, it is unlikely that there was a society without crime. The term crime conjures up such familiar images as bank robbery, assault, kidnapping, and stealing. Criminologists and other legal scholars have long wrestled with the problem of defining crime so that factors influencing it, the characteristics of criminals and the prevention of crime can be more practically addressed. Presently, there is no single definition of crime acceptable to all. In effect, a crime is anything forbidden or punishable by the criminal justice system.
There have been a number of attempts to create a consensus and an all-encompassing definition of crime. For example, Schafer and Knudten (1970) see crime as a conduct or an action that is defined and codified in Law as a crime. The section 2 of the criminal code of the Federal Republic of Nigeria-CAP77: 3151 defines crime as "an act or omission which renders the person doing the act or making the omission liable to punishment under the criminal code, under any order in council, ordinance or law or statutes". While Scott (1984), conceptualised crime as an act or default which prejudices the interest of the

A. A. Okediji, Department of Psychology, Faculty of Social Sciences, University of Uyo, Akwa Ibom State, Nigeria.

M. U. Nnamani, Department of Psychology, Faculty of Social Sciences, University of Uyo, Akwa Ibom State, Nigeria

O. O. Ojiji, The Presidency, Abuja, Nigeria.

K. B. Sanni, Educational Foundations Guidance \& Couselling, Faculty of Education, University of Uyo, Akwa Ibom State, Nigeria

O. O. Umoh, Department of Psychology, Faculty of Social Sciences, University of Uyo, Akwa Ibom State, Nigeria, 
disturbance of any interest not under the protection of criminal law, by definition, cannot be crime.

The following categorization is adopted in this study in grading offences according to their gravities: felony, misdemeanour and simple offence.

Garner (1967) defined felony as offence punishable by death or imprisonment with maximum security; misdemeanour as a lower offence punishable by fine and/or imprisonment, while simple offence is described as any offence other than felony and misdemeanour or an offence punishable by imprisonment for less than six months. This also has options of fine.

Indeed, criminal activities have cut deep and permeated several aspects of human life. And as well, human beings have equally explored and sunk deep into several aspects of criminal life. But the question remains: Why is it that given the same social situation some people tend to exhibit high criminal tendency, some others mild tendency, and yet some others are law abiding?. Perhaps, certain factors influence crime. Legal scholars including the police and forensic psychologists have made frantic efforts to identify certain factors that influence crime. Scott (1984) argues that the effects of any single factor cannot sufficiently account for crime as a whole; a number of these influences acting together can be considered significant enough to cause criminal behaviour. Feldman (1993) and Reid (2000) posit that each individual criminal act is a function of a varied number of biological, social, psychological and environmental factors with no two sets of factor necessarily alike. However, any element, whether known (e.g. psychoactive substance, gender, hunger or poverty) or otherwise not known is invariably rooted in two or more of these factors in interaction.

Certainly, psychoactive substance intake influences criminal behaviour. To this end, an individual's substance abuse habit has remained. The society's problem. It is the view of Eze and Omege (1999) that the tendency to seek pleasure from the environment in order to make live and experiences more palatable seems to take the centre stage in human behaviour. These authors have argued further that a common feature of substance abuse is that it involves a loss of selfcontrol. Eyo (2003) defined psychoactive substances as those substances that alter states of consciousness, that is, modify perception, cognition, mood and behaviours when taken into the body system. He observed further that the use of substance to modify perception is as old as the history of mankind. The drugs of abuse are broadly categorized as: Depressants (e.g. alcohol, opium), Stimulants (such as cocaine, caffeine, amphetamines), Hallucinogens (e.g (marijuana, hashish), Eze \& Omeje, 1999 ; Eyo, (2003). All the same, all psychoactive substances are also known as psychotropics. From all indications, the drugs of abuse are numerous.

However, this work aimed at studying only three - namely, alcohol, marijuana and cocaine. The researchers are interested in studying these substances because of the prevalence and incidence of their use in Nigeria, bearing in mind that these substances have quite different physiological effects on the central nervous system and the body. The researchers also believe that each of these substances induces peculiar antisocial behaviour relative to its physiological action.

Alcohol is a depressant drug. Eze and Omeje (1999) observed that alcohol comes as a colourless liquid; though other constituents of the liquid can colour it. This drug is taken orally; it acts by inhibiting neural, especially cerebral functioning and offers its peculiar form of pleasure, but at the cost of impaired thinking, memory and decisionmaking (Eyo, 2003; Halgin and Whitbourne, 2000). Marijuana is usually smoked in wraps or in pipes; and is variously referred to as grass, "igbo", "ganja", 'we-we', etc. Marijuana is usually taken to alter the perception of the user's environment and his bodily sensation. Davison and Neale (1990) postulated that the desired effects of marijuana include relaxation, heightened sense of sensuality and sexuality and increased awareness of external and internal stimuli. Conversely, a number of maladaptive behaviours may occur, including increased anxiety, distorted judgement of time and social withdrawal (Halgin \& Whitbourne, 2000). Cocaine is a stimulant drug. Cocaine, as observed by Davison and Neale (1990) has its active ingredient in coca leaves. Later, this drug was made available in commercial stuff as cocaine hydrochloride. It is odourless and white-powdered in nature.

As a matter of fact, it is likely that attempts to combat crime in a community cannot be isolated from attempts to reduce the level of substance intake in the community. McBride and McCoy (1993) concluded in this regard, that there is a strong positive correlation between drug use and criminal behaviour and that increases in substance intake is related to increases in crime. Therefore, one of the basic goals should be to develop an 
understanding of the scourge of hard drugs and identify and implement plans for its elimination.

This research also concentrated on the influence of, as well as gender gap in criminality. Coleman (2003:199) defined gender as "the behavioural, social and cultural attributes associated with sex". It is also sometimes referred to as the sexually acquired notions regarding masculinity and femininity. Myers (2002) defined gender as the characteristics people associate with male and female. It turns out that males and females are at the moment of conception different, and this difference shows itself in many systems of the body. The difference between sexes may boil down to dividing tasks of processing experiences. Thus, male's and female's minds are innately drawn to different aspects of the world around them (Marano, 2003). Wootten (1959) cited in Feldman (1993:66) states that: "if men behaved like women, the courts would be idle and the prisons empty". However, this dramatic statement overstates the true situation, but the gender gap is indeed large in this regard.

The study of crime and factors that influence it is very important to the Law Enforcement agencies, other Criminal Justice experts and mankind in general. Unfortunately, work of this nature is seriously lacking in the literature, possibly because of the sordid state of the Criminal Justice process in Nigeria. Thus, if this work meets this need, then the researchers would have filled a vacuum existing in an important research area. The implications of abusing drugs are observed in multifarious problems which affect the individual, his immediate family members and the society at large. The narrowing gender gap in criminal behaviour is also a course of concern to the society. In this study therefore, the researchers sought to proffer answers through scientific procedure to the following research questions:-

i) Does alcohol intake influence crime committed among prisoners?

ii) Does marijuana intake influence crime committed among prisoners?

iii) Is any relationship between cocaine intake and crime among prisoners?

iv) Would there be a significant gender difference in crime committed among prisoners?

Without a common understanding of essential terms and concepts, the value of research may be lost through misunderstanding and misinterpretation. For this purpose, the terms/concepts as used in this study are operationalized as follows: Psychoactive
Substance refers to alcohol, marijuana and cocaine. Gender is used to mean being a male or a female participant. Crime refers to offences punishable under the criminal law for which the participants were incarcerated, namely; felonies, misdemeanours and simple offences. Felonies refer to offences such as murder, manslaughter, stealing, robbery that are punishable with imprisonment for three years or above, e.g.. Misdemeanours refer to offences punishable by imprisonment for not less than six months, but less than three years, e.g. assault, abduction, etc. Simple offences refer to offences that are punishable by imprisonment for less than six months, e.g. gambling, traffic offences, etc. While, Prisoners are people who are incarcerated in the prison yard for various criminal offences.

Drugs are related to crime in multiple ways. Most directly, it is a crime to use, possess, manufacture, or distribute drugs (classified as having a potential for abuse such as cocaine, heroin, marijuana, and amphetamine). Drugs are also related to crime through the effects they have on the user's behaviour and by generating violence and other illegal activities that may be connected with drug trafficking (NDLEA, 1997 and F.B.I, 1998).

It has been observed that crime orientations, social relations and gender are central to understanding behaviour, especially when seen from offenders' perspectives. Marsland, et. al. (2006) interviewed eighteen convicted offenders; official data about their offence were also collected. Analysis of these data revealed two central points in participants' accounts of their involvement in crime. More positive crime orientations and more negative social relations were associated with deeper levels of involvement in crime. The analysis also indicated that these were gendered concepts, being experienced differently and having different implications for both sexes.

Many researchers concur on the importance of gender to the study of crime. King (2007) presented an article which examined the actual and potential contributions of quantitative methods of gender-crime relationship. Three bodies of literature pertaining to the gender-crime relationship were examined. They include offending, victimization, and

criminal justice processing.

The findings from this review indicate that while much knowledge about the gender-crime relationship has been uncovered by the quantitative data, a commensurate amount of 
theoretical knowledge conversely, does not exist. Other recent works, however, have suggested that masculinity is an important construct for understanding crime and violence (Messerschmitt, 1993; 1997; 2000 and Bowker, 1998). The issue of masculinity and its link to criminal behaviour in men has been identified boldly in criminological studies.

In Nigeria it might be difficult to rely on the accuracy or the appropriateness of data on type of criminality and gender in relation to psychoactive drug intake, it is against this background of the foregoing that the researchers set out to systematically find out if:

1) There will be a statistically significant influence of alcohol intake on crime committed among prisoners.

2) There will be a statistically significant influence of marijuana intake on crime committed among prisoners.

3) There will be a statistically significant degree of relatedness between cocaine intake and crime.

4) There will be a statistically significant difference between males and females on crime committed among prisoners.

\section{METHOD}

\section{Participants}

Three hundred and eighty (380) prison inmates were randomly selected from the total population of four hundred and twelve (412) prisoners incarcerated in Uyo Main Prisons. The prisoners comprised 314 males and 66 females whose ages ranged from 18 to 46 years. Their mean age was 28.3 years.

\section{Instruments}

Two instruments were used in this study. The first was a questionnaire which was used to collect some demographic data as well as data regarding the categories of offence committed by the respondents. A second instrument was a 3point Psychoactive Substance Intake Scale (PSIQ) which was used to assess alcohol, cocaine and marijuana intake. The two questionnaires were however, joined in one, not only to ease administration, but also to ensure accuracy in the arrangement of the data from each participant. The data generated was analysed using chi- square by categorizing the responses into frequencies of "most of the time" for heavy users, "sometimes" for light users, while "never" were categorized as none users.

\section{Procedure}

The research was conducted in the main yard of Uyo Prisons of the Nigerian Prison Service. A largely closed-ended questionnaire focusing directly on the respondents' drug intake before their arrest for the offence for which they were serving a sentence was randomly administered to each respondent by the researchers. Special attention was, however, given to their ability to establish rapport. In order to avoid concentration difficulties on the part of the respondents, care was taken to construct a questionnaire that needed a maximum of 30 minutes to administer. Moreover, issues in the questionnaire were dealt with in a less detailed or sensitive manner, so as to ease administration and response flow. At best, respondents were given assurance of anonymity and confidentiality regarding their identities and information they gave. Thus, the researchers apparently put it across to them that "names and addresses were not necessary for the research". The researchers also told the participants that the research aimed at discovering the best way to addressing the teaming problems in the Nigerian Prisons, most especially as it borders on the issue of over-population. The researchers were assisted by a research assistant (a Warden Officer who was officially detailed to do so). After all the questionnaires had been completed and returned, the researcher debriefed the participants on what the research was all about. Generally, the treatment of participants was in fact, in accordance with the ethical principles of psychologists (APA, 1994).

\section{Design/Statistics}

The design of the study was a survey, the participants responded to a questionnaire designed for the purpose of this study. Chi-square $\left(X^{2}\right)$ statistical technique was used for the analysis of the data collected. This was because the research bordered on the study of relationship rather than cause-effect; along side the fact that the data collected were frequency data. 


\section{RESULTS}

Table I: A 3 × 3 Contingency Table for Alcohol and Crimes.

\begin{tabular}{llllll}
\hline & & \multicolumn{2}{c}{ Alcohol } & & \\
\cline { 5 - 6 } Crime & Felony & Heavy & Light & None & Row \\
& Misdemeanor & $5.48 \%$ & $28.16 \%$ & $19.47 \%$ & $54.47 \%$ \\
& Simple offence & $3.16 \%$ & $22.63 \%$ & $3.16 \%$ & $31.58 \%$ \\
& Column & $15.76 \%$ & $58.95 \%$ & $2.63 \%$ & $13.95 \%$ \\
& & & & 25.26\% & Grand Total \\
& & & & \\
\hline
\end{tabular}

The results as presented in table 1 above show that there was a statistically significant influence of alcohol intake on crime among the participants, $\mathrm{X}^{2}(4, \mathrm{~N}=380)=29.51, \mathrm{P}<0.01$. Among heavy consumers of alcohol (15.79\%) were: $(6.84 \%), 5.79 \%$ and $3.16 \%$ who committed felony, misdemeanour and simple offence, respectively. Light takers of alcohol (58.95\%) feature prominently in crime as follows: felony $(28.16 \%)$, misdemeanour $(22.63 \%)$ and simple offence (8.16\%). Among Non-takers of alcohol, $19.47 \%, 3.16 \%$ and $2.63 \%$ accounted for felony, misdemeanour and simple offence, respectively.

Table II: A 3 x 3 Contingency Table for Marijuana Intake and Crime.

\begin{tabular}{|c|c|c|c|c|c|}
\hline & & \multicolumn{3}{|c|}{ Marijuana } & \multirow[b]{2}{*}{ Row } \\
\hline & & Heavy & Light & None & \\
\hline \multirow{4}{*}{ Crime } & Felony & $25.79 \%$ & $12.89 \%$ & $15.79 \%$ & $54.47 \%$ \\
\hline & Misdemeanor & $13.16 \%$ & $9.74 \%$ & $8.68 \%$ & $31.58 \%$ \\
\hline & Simple offence & $1.84 \%$ & $2.37 \%$ & $9.74 \%$ & $13.95 \%$ \\
\hline & Column & $40.796 \%$ & $25.00 \%$ & $34.21 \%$ & $\begin{array}{c}\text { Grand Total } \\
100 \%\end{array}$ \\
\hline
\end{tabular}

The results of the second hypothesis as presented in table 2 above indicate that there was a significant influence of marijuana intake on crimes committed among prisoners, $X^{2}(4, N=$ $380)=38.1, P<0.01)$. Heavy users of marijuana enacted more felony $(25.79 \%)$, followed by misdemeanour $(13.16 \%)$ and simple offence (1.84\%). Light users of marijuana: $12.89 \%, 9.74 \%$ and $2.37 \%$ accounted for Felony, misdemeanour and Simple offence, respectively. The results also show that non-takers of Marijuana (15.79\%) involved in felony exceeded light takers $(12.89 \%)$ in the same offence category. The total of $8.68 \%$ and $9.74 \%$ accounted for misdemeanour and simple offence, respectively.

Table III: A 3 x 3 Contingency Table Showing Cocaine Intake and Crimes among Prisoners.

\begin{tabular}{llcccc}
\hline & & \multicolumn{2}{c}{ Cocaine } & & \\
\cline { 5 - 5 } Crime & Heavy & Light & None & Row \\
& Felony & $3.94 \%$ & $12.37 \%$ & $38.16 \%$ & $54.47 \%$ \\
& Misdemeanor & $1.32 \%$ & $5.26 \%$ & $25.00 \%$ & $31.58 \%$ \\
& Simple offence & $2.11 \%$ & $4.21 \%$ & $7.63 \%$ & $13.95 \%$ \\
& Column & $7.37 \%$ & $21.84 \%$ & 70.79 & Grand Total \\
& & & & $100 \%$ \\
\hline
\end{tabular}


The results of hypothesis three as presented in table 3 above indicate that there was no statistically significant influence of cocaine intake on crimes among prisoners, $X^{2}(4, N=380)$ $=12.32$, ns). Heavy takers of cocaine $(7.37 \%)$ were involved in crime as follows: felony (3.94\%), misdemeanour $(1.32 \%)$ and simple offence $(2.11 \%)$. Light takers $(21.84 \%)$ among the prisoners were incarcerated for felony (12.37\%), misdemeanour $(5.26 \%)$ and simple offence $(4.21 \%)$. Non-takers of cocaine $(70.79 \%)$ were more than twice larger than both heavy and light takers put together: $38.16 \%, 25 \%$ and $7.63 \%$ accounted for felony, misdemeanour and simple offence, respectively.

Table IV: A $3 \times 2$ contingency table which shows gender difference in crime among prisoners.

\begin{tabular}{llccc}
\hline & \multicolumn{3}{c}{ Gender } & \\
& & Female & Male & Row Total \\
Crime & Felony & $9.21 \%$ & $45.26 \%$ & $54.47 \%$ \\
& Misdemeanor & $5.53 \%$ & $26.05 \%$ & $31.58 \%$ \\
& Simple offence & $2.63 \%$ & $11.32 \%$ & $13.95 \%$ \\
& Column Total & $17.37 \%$ & $84.63 \%$ & Grand Total \\
& & & & $100 \%$ \\
\hline
\end{tabular}

As presented in table 4 above, there was no statistically significant difference in crimes among the male and female prisoners, $X^{2}(2, N=$ $380)=0.12$, ns). A total of $45.26 \%, 26.05 \%$ and $11.32 \%$ of the males accounted for felony, misdemeanour and simple offence, respectively; whereas a the following $9.21 \%, 5.53 \%$ and $2.63 \%$ accounted for female felony, misdemeanour and simple offence, respectively.

\section{DISCUSSION}

The results supported hypotheses I and II. Hypothesis I stated that "there would be a statistically significant influence of alcohol intake on crime committed among prisoners", while hypothesis II stated that "there would be a statistically significant influence of marijuana intake on crime committed among prisoners". However, hypothesis III which stated that "there would be a significant influence of cocaine intake on crime committed" was rejected. Hypothesis IV which stated that "there would be a statistically significant difference in crimes enacted among male and female prisoners" was also rejected, on the ground that it was not supported by the research data/ results.

In this study, the finding that levels of alcohol intake influence certain categories of crime agrees with no existing findings in the previous researches (at least those reviewed by the researchers). What the majority of the researches (McBride \& McCoy, 1993; Cloward \& Ohlin, 1960; NDLEA, 1997; seem to be saying is that the general level of alcohol/drug intake and alcohol/drug-related problems correlate. The past studies ignored the fact that different categories of crime could be differently accounted for, not only by the general level of drug intake, but also by the types of substance/drug taken by the culprit before the enactment of the crime. Thus, not all drugs are the same in terms of action. The physiological effects of a particular drug determine the behavioural effects on the taker. Therefore, the depressant effect of alcohol on the central nervous system (CNS) relative to the level of intake, the amount of food in the stomach, and the personality of the taker, could account for the finding that alcohol intake influences criminal behaviour. For instance, offenders who were serving a sentence for rape particularly reported that they took alcohol immediately before or at the time of the offence that landed them in prison.

The finding that marijuana intake coexists with the category of crime committed could also be explained on the basis of its physiological action in the brain, in which case, the offences committed vary considerably according to the level of intake. Heavy takers of marijuana are more likely than light takers to engage in more violent types of crime (Aloye, 1997).

Previous finding on the general drug use as pointed out earlier was contradicted by the finding of this research on cocaine intake (before incarceration) among prison inmates. The use of cocaine seems to be quite unpopular among prisoners. This result could be due to the expensiveness of the drug. No wonder, the 
majority of those involved in the drug tended toward high crime of monetary nature, in which case, their involvement in criminal activity to support cocaine use is rampant - (committing crime to procure drugs and taking drug to engage in crime). Thus, a tendency for the onset of criminal activity to be more or less concurrent with the onset of cocaine use is very likely. It is in line with the findings of Wilson and Herrnstien (1985) which assert that it is the need to obtain money to buy the drug (cocaine) that increases crime.

The finding of this study is consistent with the findings by King (2007) and Bowker (1978) that crime orientation and gender closely intertwine. The finding of this research underscores the fact that there was no significant difference in the crime committed between male and female prisoners. This may be due to unequal number of male and female criminals with the criminal justice system in favour of males.

\section{Policy Implications of Results}

Drug does not necessarily initiate criminality, rather it tends to intensify and perpetuate them. Thus, the finding that drug intake influences crime implies that attempts to combat crime in a community cannot be isolated from attempts to reduce the level of drug intake in a community. A positive association can also be expected between drug use and recidivism. Hence, it is clear that efforts at arresting drug-related crime will have to be part and parcel of a comprehensive initiative in which agencies in criminal justice, health, education, welfare, labour and industry work in close collaboration with one another. Therefore, if the findings of this research are taken cognizance of, special attention should be given to drug-related tradition in which:

1) The prevention and treatment services should be established among the general population as well as in prisons;

2) All persons who are arrested should be screened for the use of drug through urine analysis; persons who test positive should be tested in more depth as a first step towards placing them in appropriate treatment, either while in prison or on their return to the community;

3) The government should adequately punish those involved in drug offences (cultivation, sales and usage of drugs)

4) The government and members of the society should give serious support to the police and NDLEA to carry out their statutory functions in this regard
5)

Drug education should be incorporated in the academic curricula in all educational institutions to educate the youths on the menace of hard drugs;

6) Rather than promoting drug use through advertisement, the media also should be used to enlighten the public on the dangers of drug misuse or abuse.

7) More employment opportunities should be created for the youths in this country;

8) Religious leaders, other role models and significant others should consolidate on leading and teaching the importance of living an upright life.

In conclusion, the findings of this research underscore the fact that certain crimes and certain drugs taken were significantly associated and that crimes committed among the male and female prisoners did not differ statistically. Finally, many inmates reported being lifetime substance abusers, and significant numbers admitted they had used drugs/alcohol just prior to the arrest that led to their incarceration.

\section{REFERENCES}

American Psychological Association, 1994. Ethical Principles of Psychologists. Washington D.C.: Author.

Bowker, L., 1998. Masculinity and Violence. Thousand Oaks, C. A.: Sage Publication, Inc.

Bowker, L. H., 1974. A Casual Analysis of the Drug Scene at a Seventh Day Adventist College: The Walla Walla County Drug Project. Washington.

Bowker, L. H., 1978. The Relationship between Sex, Drugs, and Sexual Behaviour on a College Campus, Drug Forum, 7, 69-80.

Cloward, R. and Ohlin, L., 1960. Delinquency and Opportunity: A theory of Delinquent Gangs. Glencoe, IL: Free Press.

Davison, G. and Neale, N. M., 1990. Abnormal Psychology $\left(5^{\text {th }}\right.$ ed.). New York: John Wiley \& Sons.

Eyo, I. E., 2003. Determinants of behaviour: Giving Meaning to Psychological Concern with Behaviour. Nsukka: AP Express Publishing. 
Eze, J. E and Omeje, O., 1999. Fundamentals of Substance Abuse. Enugu: snaap Press Ltd.

Feldman, P., 1993. The Psychology of Crime: A Social Science Textbook. New York: Cambridge University Press.

Halgin, R. P. and Whitbourne, S. K., 2000. Abnormal Psychology: Clinical Perspective on Psychological Disorders, $3^{\text {rd }}$ Edition. New York: Mc Graw Hill.

King, R. D., 2007. The Context of Marriage and Crime: Gender, the Propensity to Marry, and Offending in Early Adulthood. Criminology, 45(1):.

Marano, H. E., 2003. The New Sex Score Card. Psychology Today Magazine, 17-19. New York: Sussex Publishers.

Messerschmidt, J. W., 1993. Masculinities and Crime: Critique and Reconceptualization of Theory. Rowan \& Littlefield Publishers, Inc.
Messerschmidt, J. W., 1997. Crime as Structural Action: Gender, Race, Class and Crime in the Making. Thousand Oaks, CA: Sage.

Messerschmidt, J. W., 2000. Nine Lives Adolescent Masculinities, the Body; and violence. West view Press.

McBride, D. C., and McCoy, C. B., 1993. The Drug-Crime Relationship: An Analytical Framework. The Prison Journal, 43(3/4): 257-278.

Myers, D. G., 2002. Social Psychology, $\left(7^{\text {th }}\right.$ Ed.). New York: McGraw Hill Companies.

National Drug Law Enforcement Agency, 1997. 1997 Drug Data Collection and Research. Lagos: Drug Demand Reduction Unit, National Drug Law Enforcement Agency.

Wilson, J. and Herrnstein, R., 1985. Crime and Human Nature, New York: Simon \& Schuster. 